\title{
Anxiety and Hippocampus Volume in the Rat
}

\author{
Raffael Kalisch*,1,3, Mirjam Schubert ${ }^{1,3}$, Wolfgang Jacob², Melanie S Keßler², Rosa Hemauer', \\ Alexandra Wigger ${ }^{2}$, Rainer Landgraf ${ }^{2}$ and Dorothee P Auer' \\ 'NMR Study Group, Max-Planck-Institute of Psychiatry, Munich, Germany; ${ }^{2}$ Behavioral Neuroendocrinology, Max-Planck-Institute of Psychiatry, \\ Munich, Germany
}

\begin{abstract}
In depressed patients as well as healthy controls, a positive relationship between hippocampal volume and trait anxiety has been reported. This study sought to explore the possible inter-relation between hippocampal volume and trait anxiety further. Magnetic resonance imaging at $7 \mathrm{~T}$ was used to measure hippocampal volumes in a rat model of extremes in trait anxiety (experiment 1 ) and in a Wistar population with normal anxiety-related behavior (experiment 2). In addition to anxiety-related behavior, potentially confounding factors (depression-like, exploratory, and locomotor behavior) were assessed. Experiment I globally supported the hypothesis of a positive relationship between hippocampus volume and trait anxiety but did not allow for ruling out possible confounds arising from cosegregation of other behavioral traits. Experiment 2 yielded strong evidence for a negative relationship which was specific for trait anxiety. Thus, the relationship between hippocampal volume and anxiety may be more complex than expected. Interestingly, anxietyrelated behavior in experiment 2 had a stronger influence on hippocampal volume than depression-like behavior. In the light of hippocampal volume loss in anxiety disorder and frequent comorbidity of anxiety and depression, this finding suggests that further research into the relationship between anxiety and hippocampal volume may be critical for understanding hippocampal contributions to normal and pathological behavior.

Neuropsychopharmacology (2006) 3 I, 925-932. doi:I 0.I038/sj.npp. I 3009 I0; published online 28 September 2005
\end{abstract}

Keywords: hippocampus; anxiety; HAB; magnetic resonance imaging; volumetry; rat

\section{INTRODUCTION}

Hippocampal volume is reduced in patients with longstanding depression (Campbell et al, 2004; Videbech and Ravnkilde, 2004) and severe, unremitting post-traumatic stress disorder (PTSD; Bremner et al, 1995, 1997; Gilbertson et al, 2002; Gurvits et al, 1996; Lindauer et al, 2004; Stein et al, 1997; Villarreal et al, 2002).

The mechanisms underlying these volume reductions are largely unclear. Animal models have played an important role in developing the two major theories in the field, namely that stress-related hypercortisolemia causes hippocampal atrophy (McEwen, 2000) and that hippocampal volume is heritable and a cause of, rather than a result of, increased stress susceptibility (Lyons et al, 2001).

Since ethical reasons naturally limit the possibility for mechanistic investigation in humans, animal models will continue to be of critical importance. Another factor

\footnotetext{
*Correspondence: Dr R Kalisch, Functional Imaging Laboratory (FIL), Wellcome Department of Imaging Neuroscience, University College London, 12 Queen Square, London WCIN 3BG, UK, Tel: + 44207 833 7479, Fax: + 442078 I 3 1420, E-mail: rkalisch@fil.ion.ucl.ac.uk ${ }^{3}$ Both these authors have contributed equally to this work.

Received 20 December 2004; revised 5 July 2005; accepted 24 August 2005

Online publication: 31 August 2005 at http://www.acnp.org/citations/ Npp083 105040599/default.pdf
}

limiting research in human models is that psychiatric diagnoses (American Psychiatric Association, 2000) are, at present, purely symptom-based. A diagnosis like depression, for example, may actually encompass several diseases with similar symptoms but different underlying pathogenetic mechanisms.

To account for such heterogeneity, several researchers have included additional trait factors such as anxiety, intelligence, alcoholism, or illness-related factors such as illness duration, age of onset, or trauma exposure in their studies. In a number of cases, such trait factors indeed had a significant influence on hippocampal volume (eg, De Bellis et al, 2002; Fennema-Notestine et al, 2002; Gurvits et al, 1996; Lindauer et al, 2004; MacQueen et al, 2003; Rusch et al, 2001; Villarreal et al, 2002). While this approach cannot provide mechanistic information, it can 'refine' a diagnosis with the help of theoretically and operationally better defined entities. As a consequence, it can help clarify which aspects of the depression or PTSD syndrome groups are associated with changes in hippocampal volume and thus generate detailed hypotheses for mechanistic investigation in animal models.

An especially interesting finding resulting from this strategy was reported by Rusch et al (2001). The authors showed that trait anxiety is positively related to hippocampal volume in both depressed patients and normal controls. At first sight, the result is surprising because (i) 
anxiety and depression are highly comorbid, (ii) PTSD, which is one of the major anxiety disorders, is characterized by volume loss (see above), and (iii) disorders of the anxiety spectrum are, similar to depressive disorder, often associated with stress hormone axis hyperfunction (Rasmusson et al, 2003). Thus, intuitively, one would expect anxiety to be linked with hippocampal volume reduction rather than enlargement.

On the other hand, one of the major neuroanatomical theories of anxiety (Gray and McNaughton, 2000) claims a crucial role for the hippocampal formation in anxiety behavior. Thus, enlarged hippocampal volume in anxious individuals could reflect increased use, similar to the observed increase in navigation-related areas in taxi drivers (Maguire et al, 2000) and speech-related areas in bilingual subjects (Mechelli et al, 2004).

The observation made by Rusch et al (2001) of larger right-sided hippocampi in anxious subjects can be held to further support the Gray/McNaughton theory and therefore warrants replication. Furthermore, given the wealth of molecular data now available on anxiety in rats and mice, independent confirmation in a rodent model would open up new avenues to investigate the molecular mechanisms underlying altered hippocampal morphology and function, reaching beyond the 'classical' hypercortisolemia theory.

To clarify the relationship between trait anxiety and hippocampal volume, we here explicitly tested the hypothesis of a positive relationship between hippocampal volume and trait anxiety in two experiments. In the first experiment, we used a well-characterized rat model wherein genetic selection for anxiety-related behavior on the elevated plus maze has resulted in extreme anxiety phenotypes, called the high (HAB) and low anxiety-related behavior (LAB) lines (Landgraf and Wigger, 2002, 2003). The extreme behavioral divergence should increase the probability of finding hippocampal volume differences if hippocampal volume indeed depends on anxiety. Furthermore, first cellular (Salome et al, 2004) and molecular (Murgatroyd et al, 2004) data from this rat model are now emerging. In the second experiment, we used a Wistar population which was not specifically bred for anxietyrelated behavior and thus exhibited normal anxiety (here called 'NABs').

Importantly, as we expected potential confounding effects resulting from cosegregated depression-like behavior, which can be expected to reduce hippocampal volume (see above), and possibly from exploratory behavior (Crusio et al, 1989), all animals underwent behavioral testing for these traits. The tests also allowed us to assess locomotor activity.

\section{MATERIALS AND METHODS}

\section{Animals}

Eight male HAB (mean age $106 \pm 0$ (SEM) days), eight male LAB (mean age $108 \pm 0.49$ days), and 16 male NAB rats (purchased from C. River, Germany, mean weight $351 \pm 11 \mathrm{~g}$ ) were used. Animals were kept in standard cages in groups of up to five in a conventional animal facility $(12: 12 \mathrm{~h}$ light/dark cycle with lights on at $06: 00 \mathrm{~h}$, $22^{\circ} \mathrm{C}, 60 \%$ humidity) with free access to food (Altromin 1314) and water.

All procedures described below were approved by local authorities according to national and regional governmental rules.

\section{Elevated Plus Maze}

The elevated plus maze (EPM; Pellow et al, 1985) is based on the animal's conflict between the innate fear of open elevated places and the drive to explore new areas. The degree of avoidance of the open arms of the maze is considered a measure of the genetic predisposition, that is, trait anxiety, and is predictive of behavior in other tests of anxiety (Henderson et al, 2004; Trullas and Skolnick, 1993).

The EPM was made of dark gray PVC and consisted of a plus-shaped platform elevated $73 \mathrm{~cm}$ from the floor. Two of the opposing arms $\left(50 \times 10 \mathrm{~cm}^{2}\right)$ were enclosed by $38 \mathrm{~cm}$ high side and end walls (closed arms). The four arms were connected by a central platform $\left(10 \times 10 \mathrm{~cm}^{2}\right)$.

At the beginning of each 5-min trial, the rat was placed on the central platform facing a closed arm. The apparatus was cleaned before and after each test session with water containing a detergent.

Behavior was monitored via a video camera fixed above the EPM. The time spent on both types of arms, the number of entries into both types of arms and the latency to the first entry into any of the open arms were determined by a trained observer blind to treatment using a computer program (PLUSMAZE, Scheidemann, Germany). From this, the following scores were computed: \%EOA: percent entries into open arm (inversely related to anxiety); \%TOA: percent time spent on open arm (inversely related to anxiety); LATOA: latency to first entry into open arm (positively related to anxiety); and NECA: number of entries into closed arms (a measure of locomotor activity).

\section{Forced Swim Test}

The forced swim test (Porsolt et al, 1978) is based on the observation that rats, when forced to swim in a cylinder from which they cannot escape, will after some time adopt a characteristic immobile posture (floating). Floating is reduced by antidepressant drugs but not sensitive to anxiolytics.

In our adapted version of the forced swim test (Keck et al, 2003), the cylinder (height $60 \mathrm{~cm}$, diameter $40 \mathrm{~cm}$, Plexiglass) was filled with $19^{\circ} \mathrm{C}$ tap water to a height of $50 \mathrm{~cm}$. After the swim session, the rat was dried with a towel and placed back into the home cage. The rat's behavior during the 10-min trial was recorded and the following parameters were scored by a trained observer blind to treatment using a computer program (Eventlog 1.0, Henderson, Germany): TSTR: time spent struggling (inversely related to depression); TFLO: time spent floating (positively related to depression); LATFLO: latency to float (inversely related to depression).

\section{Open Field Test}

The open field test (Hall, 1934) is normally used to assess emotionality based on the same conflict situation as in the EPM. When the test duration is extended to $30 \mathrm{~min}$, 
habituation to the emotionally challenging situation occurs and the test then measures locomotor and exploratory activity (Crusio et al, 1989).

The open field $\left(54 \times 48 \mathrm{~cm}^{2}\right.$, walls $51 \mathrm{~cm}$ high, wood, 300 lux illumination) was divided into an inner $\left(28 \times 33 \mathrm{~cm}^{2}\right)$ and an outer area by a line on the floor. Animals were placed in the center of the field and observed for $30 \mathrm{~min}$. Between trials, the chamber was cleaned with $5 \%$ alcohol. The following parameters were obtained for each of three consecutive 10-min-intervals: NREAR1, NREAR2, NREAR3: number of rearings during first, second, and third intervals (a measure of exploration); NCROSS1, NCROSS2, NCROSS3: number of line crossings from inner into outer area or vice versa during first first, second, and third intervals (a measure of locomotion). A rat was considered to have entered the inner or outer area when two feet had gone past the dividing line.

All behavioral measures (Table 1) were in accordance with previous literature (Landgraf and Neumann, 2004; Landgraf and Wigger, 2002, 2003; Wigger et al, 2004).

\section{Volumetry}

Hippocampal volumetry was performed using noninvasive magnetic resonance imaging (MRI) because this allowed us to also measure the response of hippocampal volume to (subsequent) pharmacologic intervention in a withinsubject design. Results of the longitudinal study will be reported elsewhere.

Animals were treated as previously described (Kalisch et al, 2001). Briefly, animals were mechanically ventilated under $1.6 \%$ isoflurane and placed in a custom-made head holder with an integrated receive-only surface head coil specially designed for rat brain ( $\mathrm{M}$ Neumeier, Boehringer Ingelheim, Germany). Body temperature $\left(38.0 \pm 0.5^{\circ} \mathrm{C}\right)$ and expiratory $\mathrm{CO}_{2}(35-40 \mathrm{mmHg})$ were kept constant throughout the experiment.

Scans were performed on a Bruker $7 \mathrm{~T}$ Avance Biospec 70/30 magnet (Bruker, Germany). A rapid-acquisition relaxation-enhancement (RARE) sequence was used for structural imaging $\left(\mathrm{TR}=4000 \mathrm{~ms}, \mathrm{TE}=19.4 \mathrm{~ms}, \mathrm{TE}_{\text {eff }}=43.8 \mathrm{~ms}\right.$, echo train length: 4 , number of averages: 6 , number of slices: 30 , slice orientation: axial, slice thickness: $0.75 \mathrm{~mm}$, inter-slice gap: $0.1 \mathrm{~mm}$, field of view: $3.5 \times 3.5 \mathrm{~cm}^{2}$, matrix: $512 \times 384$, resulting in a spatial resolution of $0.068 \times 0.068 \times 0.75 \mathrm{~mm}^{3}$, scan duration: $39 \mathrm{~min} 19 \mathrm{~s}$; see Figure 1). For reproducible anatomical location of the slice package, a series of localizer scans was used to define three mutually orthogonal planes (transversal, horizontal, sagittal). The slice package was then positioned perpendicular to a line connecting the superior end of the olfactory bulb and the superior end of the cerebellum according to Wolf et al (2002), with the first slice located at the most anterior point of the olfactory bulb. This resulted in whole brain coverage (ie, including olfactory bulb and cerebellum).

Using the manufacturer's ROITool software, right (RHV) and left hippocampal (LHV) and brain volumes (BV) were manually outlined by two raters (RK, MS) blinded to group status. Hippocampal tissue borders were defined according to Wolf et al (2002) and using a standard rat brain atlas (Paxinos and Watson, 1998) for reference (Figure 1). Thus,

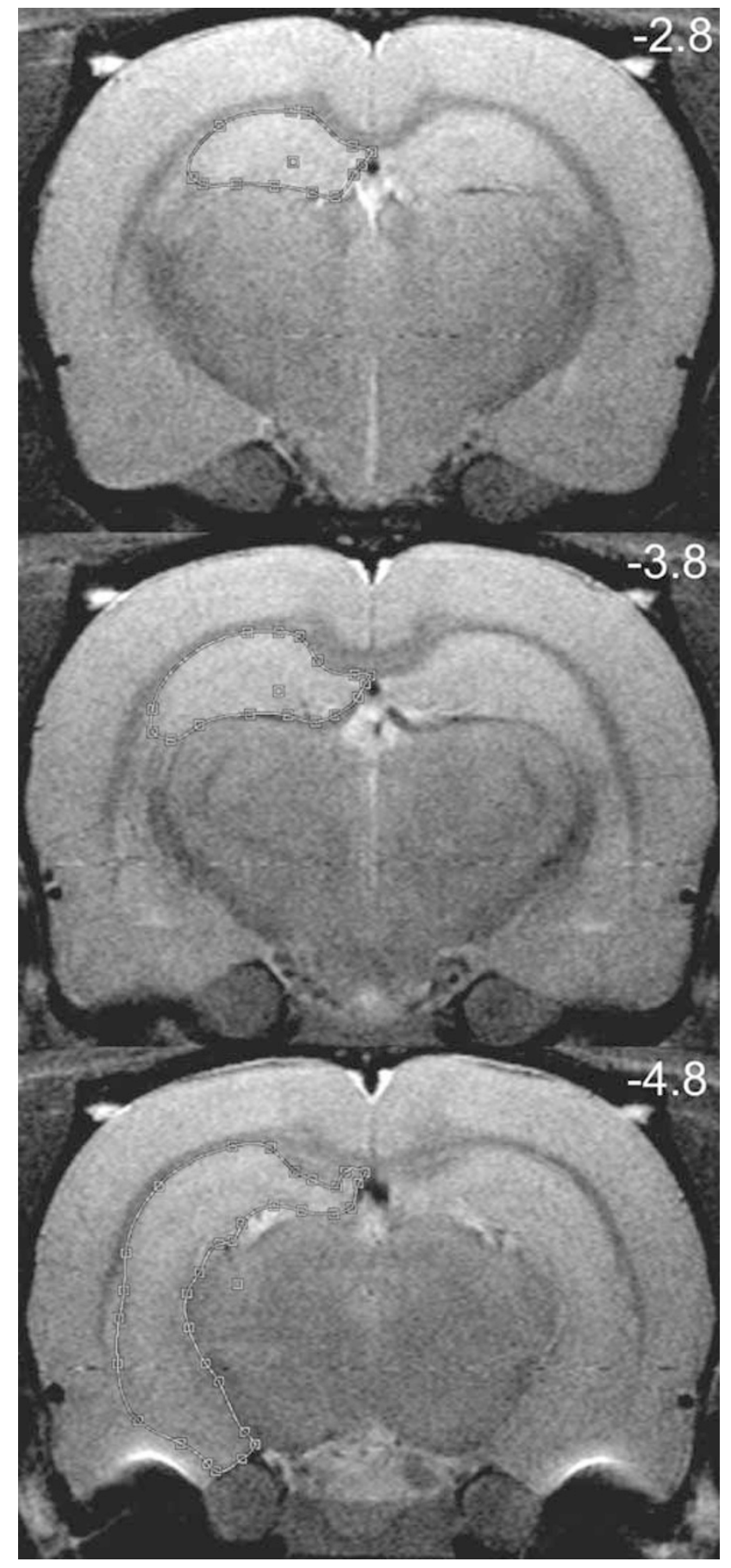

Figure I Volumetry. Example of a volumetric scan and delineated left hippocampus. Numbers show approximate distance from bregma in $\mathrm{mm}$.

the most anterior hippocampal slice included corresponded to a level of approximately $-2.12 \mathrm{~mm}$ posterior to bregma; the most posterior hippocampal slice included corresponded to a level of approximately -7.04 posterior to bregma. Hippocampal structures were identified on seven to eight consecutive slices in the individual animals.

For determination of $\mathrm{BV}$, the most anterior brain slice included was the first slice in which prefrontal cortex covered $\geqslant 50 \%$ of the brain tissue, and therefore included caudal parts of the olfactory bulb. This corresponded to a 
level of approximately $4.20 \mathrm{~mm}$ anterior to bregma. The most posterior brain slice included was the last slice anterior to the cerebellum and usually covered the central nucleus of inferior colliculus and the caudal end of the aqueduct. This corresponded to a level of approximately $-8.8 \mathrm{~mm}$ posterior to bregma. The entire included brain tissue was distributed over 14-16 consecutive slices in the individual animals.

Volumes were calculated by multiplying the outlined area in each slice by the inter-slice interval $(0.75 \mathrm{~mm}$ slice + $0.1 \mathrm{~mm}$ gap $=0.85 \mathrm{~mm}$ ). For the last slice, the multiplicator was $0.75 \mathrm{~mm}$. Left-sided hippocampal dominance (ASY) was defined as: (LHV-RHV/LHV + RHV) 100 with LHV being the left hippocampal volume and RHV the right hippocampal volume.

All volumetric data represent average ratings from the two raters. In experiment 1 , one animal's BV could only be determined by rater 1 due to a technical problem. Interrater correlations (Spearman) were $r=0.75$ for RHV, $r=0.85$ for LHV, $r=0.75$ for total hippocampal volume (THV), and $r=1.0$ for $\mathrm{BV}$ in experiment 1 and $r=0.64$ (RHV), $r=0.71$ (LHV), $r=0.64$ (THV), and $r=0.97$ (BV) in experiment 2.

\section{Statistical Analysis}

Statistical analysis was carried out within SPSS11 using bivariate correlations, Student's $t$-test, multivariate analysis of variance (MANOVA) or covariance (MANCOVA), and multiple regression analysis. Since THV is linearly dependent on LHV and RHV, separate univariate analyses of variance (ANOVA) or covariance (ANCOVA) were used to test for group differences in this variable.

\section{RESULTS}

Tables 1 and 2 show physiological, volumetric and behavioral measures of $\mathrm{HAB}, \mathrm{LAB}$ and $\mathrm{NAB}$ rats.

\section{Experiment 1: HAB and LAB Rats}

Hippocampal volume. The group data suggest that HABs have larger hippocampal volumes than LABs (Table 1). To formally test for group differences in volumetric measures and for the potential influence of body weight (BW) differences (see Table 1), a MANCOVA with RHV and LHV and BV as dependent variables, group as independent variable and $\mathrm{BW}$ as covariate was calculated. There were significant effects of group $(\mathrm{F}(3,11)=17.71, p<0.001)$ and BW $(F(3,11)=11.03, p=0.001)$. The group effects adjusted for BW were significant for $\mathrm{RHV}(\mathrm{F}(1,13)=25.72, p<0.001$, univariate $\mathrm{F}$ test $)$ and $\operatorname{LHV}(\mathrm{F}(1,13)=40.79, p<0.001)$ but not for $\mathrm{BV}(\mathrm{F}(1,13)=2.46, p=0.141)$. An ANCOVA with THV as dependent variable, group as independent variable, and BW as covariate also showed significant effects of group $(\mathrm{F}(1,13)=30.29, p<0.001)$ and $\mathrm{BW}(\mathrm{F}(1,13)=10.82$, $p=0.006)$. The apparent hippocampal volumetric group differences thus survived correction for BW.

A MANCOVA with normalized right (RHV/BV) and left (LHV/BV) hippocampal volumes as dependent variables,
Table I Experiment I: Physiological, Volumetric and Behavioral Measures in $H A B$ and $L A B$ Rats

\begin{tabular}{|c|c|c|c|c|}
\hline Measure & $\begin{array}{l}\text { Behavioral } \\
\text { category }\end{array}$ & $\begin{array}{c}\text { HAB } \\
(n=8)\end{array}$ & $\begin{array}{c}\text { LAB } \\
(n=8)\end{array}$ & $\begin{array}{l}\text { HAB vs } \\
\text { LAB (p) }\end{array}$ \\
\hline \multicolumn{5}{|c|}{ Physiological measures } \\
\hline BW (g) & & $326 \pm 13$ & $356 \pm 4$ & $0.049 *$ \\
\hline \multicolumn{5}{|c|}{ Volumetric measures } \\
\hline $\mathrm{BV}\left(\mathrm{mm}^{3}\right)$ & & $1286.12 \pm 20.65$ & $1300.84 \pm 11.0$ & 0.539 \\
\hline $\mathrm{RHV}\left(\mathrm{mm}^{3}\right)$ & & $50.85 \pm 0.67$ & $47.89 \pm 0.65$ & $0.007 *$ \\
\hline $\mathrm{LHV}\left(\mathrm{mm}^{3}\right)$ & & $50.08 \pm 0.78$ & $47.58 \pm 0.57$ & $0.021 *$ \\
\hline $\mathrm{THV}\left(\mathrm{mm}^{3}\right)$ & & $101.71 \pm 1.40$ & $95.47 \pm 1.17$ & $0.004 *$ \\
\hline RHV/BV (\%) & & $3.96 \pm 0.03$ & $3.68 \pm 0.03$ & $0.000 *$ \\
\hline LHV/BV (\%) & & $3.89 \pm 0.02$ & $3.66 \pm 0.02$ & $0.000 *$ \\
\hline THV/BV (\%) & & $7.91 \pm 0.07$ & $7.34 \pm 0.05$ & $0.000 *$ \\
\hline ASY & & $-0.78 \pm 0.22$ & $-0.31 \pm 0.34$ & 0.266 \\
\hline
\end{tabular}

Behavioral measures

Elevated plus maze

\%TOA (\%) Anxiety (inv.)

LATOA (s) Anxiety

NECA Locomotion

Forced swim test

$\begin{array}{lllcl}\text { TSTR (s) } & \text { Depression (inv.) } & 17.5 \pm 2.8 & 55.0 \pm 7.4 & 0.000 * \\ \text { TFLO (s) } & \text { Depression } & 78.5 \pm 19.8 & 35.4 \pm 5.2 & 0.054 \\ \text { LATFLO (s) Depression } & 49.7 \pm 4.1 & 102.0 \pm 19.0 & 0.017 * 6\end{array}$

Open field test

$\begin{array}{llrrr}\text { NREARI } & \text { Exploration } & 31.3 \pm 3.3 & 41.6 \pm 3.3 & 0.042^{*} \\ \text { NREAR2 } & \text { Exploration } & 10.9 \pm 3.0 & 27.0 \pm 3.3 & 0.003^{*} \\ \text { NREAR3 } & \text { Exploration } & 4.5 \pm 1.4 & 20.0 \pm 2.2 & 0.000^{*} \\ \text { NCROSSI } & \text { Locomotion } & 4.8 \pm 0.7 & 13.4 \pm 1.4 & 0.000^{*} \\ \text { NCROSS2 } & \text { Locomotion } & 1.5 \pm 0.5 & 9.5 \pm 1.6 & 0.000^{*} \\ \text { NCROSS3 } & \text { Locomotion } & 0.8 \pm 0.4 & 6.0 \pm 1.9 & 0.017 *\end{array}$

* difference HAB vs LAB significant at $p<0.05$ ( $t$-test, two-tailed).

inv:: inversely related; $B V$ : brain volume; RHV: right hippocampal volume; LHV: left hippocampal volume; THV: total hippocampal volume; ASY: left-sided hipppocampal dominance; \%EOA: percent entries into open arm; \%TOA: percent time spent on open arm; LATOA: latency to enter into open arm; NECA: number of entries into closed arms; TSTR: time spent struggling; TFLO: time spent floating; LATFLO: latency to float; NEARI: number of rearings during minutes I-10; NREAR2: number of rearings during minutes I I-20; NREAR3: number of rearings during minutes 21-30; NCROSS I: number of line crossings during minutes I-I0; NCROSS2: number of line crossings during minutes I I-20; NCROSS3: number of line crossings during minutes 21-30.

group as independent variable, and BW as covariate showed a significant effect of group $(\mathrm{F}(2,12)=21.17, p<0.001)$ but not of $\mathrm{BW}(\mathrm{F}(2,12)=2.14, p=0.16)$. The group effects adjusted for $\mathrm{BW}$ were significant for both RHV/BV $(\mathrm{F}(1,13)=25.81, p<0.001)$ and LHV/BV $(\mathrm{F}(1,13)=45.78$, $p<0.001)$. An ANCOVA with THV/BV as dependent variable, group as independent variable, and BW as covariate likewise 
Table 2 Experiment 2: Physiological, Volumetric and Behavioral Measures in NAB Rats

\begin{tabular}{|c|c|c|}
\hline Measure & Behavioral category & $\operatorname{NAB}(n=16)$ \\
\hline \multicolumn{3}{|c|}{ Physiological measures } \\
\hline BW (g) & & $351 \pm 11$ \\
\hline \multicolumn{3}{|l|}{ Volumetric measures } \\
\hline $\mathrm{BV}\left(\mathrm{mm}^{3}\right)$ & & $1338.27 \pm \mid 1.82$ \\
\hline $\mathrm{RHV}\left(\mathrm{mm}^{3}\right)$ & & $49.83 \pm 0.58$ \\
\hline $\mathrm{LHV}\left(\mathrm{mm}^{3}\right)$ & & $49.42 \pm 0.71$ \\
\hline $\mathrm{THV}\left(\mathrm{mm}^{3}\right)$ & & $99.25 \pm 1.28$ \\
\hline RHV/BV (\%) & & $3.72 \pm 0.03$ \\
\hline LHV/BV (\%) & & $3.69 \pm 0.04$ \\
\hline THV/BV (\%) & & $7.42 \pm 0.06$ \\
\hline ASY & & $-0.44 \pm 0.25$ \\
\hline \multicolumn{3}{|l|}{ Behavioral measures } \\
\hline \multicolumn{3}{|c|}{ Elevated plus maze } \\
\hline \%EOA (\%) & Anxiety (inv.) & $25.7 \pm 3.6$ \\
\hline \%TOA (\%) & Anxiety (inv.) & $18.8 \pm 3.7$ \\
\hline LATOA (s) & Anxiety & $91.4 \pm 27.5$ \\
\hline NECA & Locomotion & $9.6 \pm 0.9$ \\
\hline \multicolumn{3}{|c|}{ Forced swim test } \\
\hline $\operatorname{TSTR}(\mathrm{s})$ & Depression (inv.) & $40.9 \pm 4.7$ \\
\hline TFLO (s) & Depression & $36.4 \pm 5.8$ \\
\hline LATFLO (s) & Depression & $111.2 \pm 13.1$ \\
\hline \multicolumn{3}{|l|}{ Open field test } \\
\hline NREARI & Exploration & $53.2 \pm 3.56$ \\
\hline NREAR2 & Exploration & $23.2 \pm 2.5$ \\
\hline NREAR3 & Exploration & $10.8 \pm 1.7$ \\
\hline NCROSSI & Locomotion & $11 \pm 1.2$ \\
\hline NCROSS2 & Locomotion & $5.5 \pm 1.5$ \\
\hline NCROSS3 & Locomotion & $3.3 \pm 0.8$ \\
\hline
\end{tabular}

showed a significant effect of group $(\mathrm{F}(1,13)=27.10$, $p<0.001)$ but not of $\mathrm{BW}(\mathrm{F}(1,13)=0.68, p=0.425)$. That is, normalized hippocampal volumes, like un-normalized volumes, showed group differences that survived correction for $\mathrm{BW}$. The results suggest that normalization for BV inherently corrects for influences of BW. Therefore, only normalized volumes are used in the following.

Behavior. To assess group effects on behavioral measures, the behavioral measures showing the strongest $t$-test group difference in each behavioral category (see Table 1) were used as dependent variables (\%TOA for anxiety, TSTR for depression, NCROSS1 for locomotion and NREAR3 for exploration). A MANCOVA with group as independent variable and $\mathrm{BW}$ as covariate showed a significant effect of group $(\mathrm{F}(4,10)=21.77, \quad p<0.001)$ but not of BW $(\mathrm{F}(4,10)=0.15, p=0.061)$. Adjusted group effects were significant for all four behavioral measures ( $p \leqslant 0.005$ each).

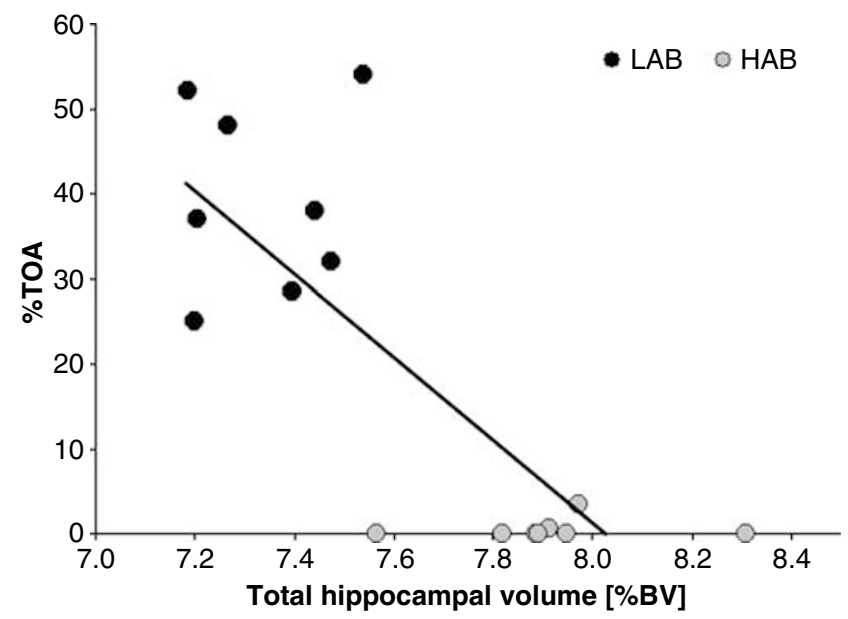

Figure 2 Experiment I ( $H A B$ and $L A B$ rats). The percent of time spent on the open arms of an elevated plus maze (\%TOA), an inverse measure of anxiety, is negatively correlated to normalized total hippocampal volume (as percent of brain volume (BV)) across $\mathrm{HAB}$ and $\mathrm{LAB}$ rats. $r=-0.80$, $p<0.00 \mathrm{l}$. Note the strongly dichotomous distribution of \%TOA between the groups, accompanied by an apparent absence of within-group correlations.

Relation between hippocampal volume and behavior. The confirmed observation of larger hippocampal volumes in the hyperanxious $\mathrm{HAB}$ rats suggests a positive relationship between trait anxiety and hippocampal volume. Indeed, $\% \mathrm{TOA}$, which is an inverse measure of anxiety, was significantly negatively correlated with RHV/BV (Pearson's $r=-0.77, p<0.001)$, LHV/BV $(r=-0.86, p<0.001)$ and THV/BV $(r=-0.80, p<0.001$; Figure 2$)$. Taken together, the data from $\mathrm{HAB}$ and $\mathrm{LAB}$ rats globally support our hypothesis.

A potential caveat becomes apparent when inspecting Figure 2, which indicates that the strong correlations observed may simply reflect a dichotomous distribution of \%TOA between the two groups. This leaves open the possibility that other physiological or behavioral group differences with a similar dichotomous distribution (such as depression-like, exploratory, or locomotor behavior, see Table 1) may account for the observed volumetric differences. Accordingly, we also observed significant negative relationships between TSTR, NCROSS1, and NREAR3 and each of the three volumetric measures above (not shown). The argument of potential nonspecificity was further strengthened by an absence of within-group correlations between anxiety and hippocampal volume in both HABs $(p \geqslant 0.67)$ and LABs $(p \geqslant 0.53)$. Within-group analysis, however, was hampered by limited sample size ( $n=8$ per group), the small spread of \%TOA within each group, and a possible floor effect in HABs (see Figure 2), precluding firm conclusions. Ultimately, experiment 1 therefore did not allow us to reject our hypothesis but did not yield unequivocal support either.

\section{Experiment 2: NAB Rats}

The ambiguous results from experiment 1 prompted us to investigate trait-volume relationships in a normal rat population that does not present problems of cosegregation of behavioral traits. 


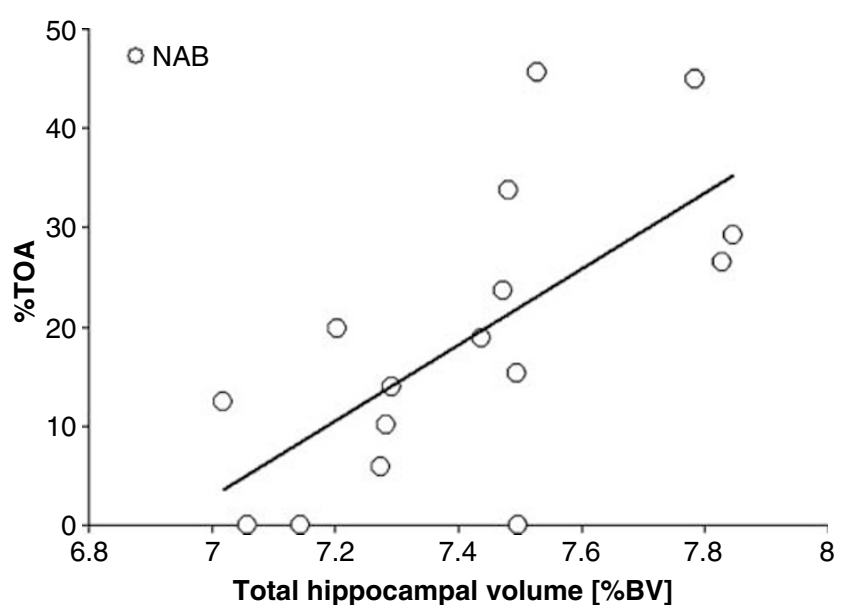

Figure 3 Experiment 2 ( $N A B$ rats). The percent of time spent on the open arms of an elevated plus maze (\%TOA), an inverse measure of anxiety, is positively correlated to normalized left hippocampal volume (as percent of brain volume (BV)) in NAB rats. $r=0.67, p=0.005$. This indicates that anxiety is negatively, rather than positively, correlated to (left) hippocampal volume.

Hippocampal volume. In $\mathrm{NAB}$ rats, $\mathrm{BW}$ was significantly correlated with $\mathrm{BV}(r=0.52, p=0.039)$ but not with RHV, LHV, or THV. When normalizing hippocampal volumes to $\mathrm{BV}$, correlations with BW approached zero.

Relation between hippocampal volume and behavior. Unlike in experiment 1, correlations of \%TOA (inversely related to anxiety) with normalized hippocampal volumes were positive (RHV/BV: $r=0.58, p=0.018 ;$ LHV/BV: $r=0.70, p=0.002$; THV/BV: $r=0.67, p=0.005$; Figure 3 ). We note that $p$-values for the LHV/BV and THV/BV correlations survive Bonferroni correction for multiple comparisons (threshold: $p=0.0167$ ). Bonferroni correction is overconservative in this context because the different hippocampal volume measures are highly significantly correlated to each other (not shown) and thus not independent. This underlines the strength of the observed effect. Further corroborating a negative relationship between anxiety and hippocampal volumes in $\mathrm{NAB}$ rats, we found similar but smaller positive correlations between \%EOA, which is also inversely related to anxiety, and hippocampal volumes $(p<0.05$ for LHV/BV and THV/BV) and negative but nonsignificant correlations between LATOA (positively related to anxiety) and hippocampal volumes (not shown).

Thus, experiment 2 using rats with normal anxiety behavior found strong support for a negative relationship between trait anxiety and hippocampal volume.

\section{Multiple Regression Analysis}

Simple regression analysis does not take into account the possible influence of other behavioral variables shown earlier to differ between $\mathrm{HAB}$ and $\mathrm{LAB}$ rats (in particular TSTR, NCROSS1, NREAR3). We therefore attempted to calculate a multiple regression of \%TOA and the other three behavioral variables on hippocampal volume across all three animal groups (total $n=32$ ). However, the four regressors were all significantly correlated with each other.
Table 3 Relationship between Behavior and Hippocampal Volume in NAB Rats

\begin{tabular}{|c|c|c|c|c|c|c|}
\hline \multirow{2}{*}{$\begin{array}{l}\text { Dependent variables } \\
\text { Independent variables }\end{array}$} & \multicolumn{2}{|c|}{ RHV/BV } & \multicolumn{2}{|c|}{ LHV/BV } & \multicolumn{2}{|c|}{ THV/BV } \\
\hline & Beta & $p$ & Beta & $p$ & Beta & $p$ \\
\hline \%TOA & 0.565 & 0.030 & 0.653 & 0.005 & 0.633 & 0.009 \\
\hline TSTR & -0.266 & 0.256 & -0.336 & 0.093 & -0.315 & 0.135 \\
\hline NREAR3 & 0.136 & 0.557 & 0.062 & 0.747 & 0.097 & 0.634 \\
\hline
\end{tabular}

Three separate multiple regression analyses of group and behavioral variables on whole-brain normalized hippocampal volumes were performed.

$\mathrm{RHV}$ : right; LHV: left; THV: total hippocampal volume; BV: brain volume; \%TOA: percent time spent on open arm (inversely related to anxiety); TSTR: time spent struggling (a measure of depression-like behavior); NEAR3: number of rearings during minutes $2 \mathrm{I}-30$ (a measure of exploratory behavior).

The same applied when looking at $\mathrm{HAB}$ and $\mathrm{LAB}$ rats only, in line with coselection of traits within this anxiety model.

By contrast, there was no collinearity between the four regressors within the NAB group $(p \geqslant 0.365)$, with the exception of a trend-level collinearity $(p=0.061)$ between NCROSS1 and NREAR3. We therefore restricted multiple regression analysis to $\mathrm{NAB}$ rats.

To retain statistical power given a reduced sample size of $n=16$ and because we found no evidence for a role of locomotion in the volumetric literature, only \%TOA, TSTR, and NREAR3 were used as regressors. Three separate multiple regression analyses investigated their influence on $\mathrm{RHV} / \mathrm{BV}, \mathrm{LHV} / \mathrm{BV}$, and THV/BV, respectively.

The analyses explained 43,61 , and $56 \%$ of the total variance, respectively, indicating a linear combination of the behavioral variables only partly accounted for volumetric variability. A significant positive relationship between \%TOA (inversely related to anxiety) and hippocampal volume was observed in all three analyses while none of the other independent variables were significantly related to hippocampal volume (Table 3). Thus, multiple regression analysis in $\mathrm{NAB}$ rats yielded additional evidence for a negative relationship between trait anxiety and left hippocampal volume that cannot be explained by the influence of other behavioral traits.

\section{DISCUSSION}

The presented data do not unequivocally support the hypothesis, based on findings by Rusch et al (2001) in humans, that hippocampal volume is positively correlated to trait anxiety in the rat. While, as predicted, the hyperanxious $\mathrm{HAB}$ rats had larger hippocampal volumes than the hypoanxious LAB rats (experiment 1 ) and showed a positive relationship between hippocampal volume and anxiety, we were unable to rule out possible effects from other cosegregated behavioral traits. Contrary to our predictions, the experiment in $\mathrm{NAB}$ rats provided strong evidence for a negative relationship between anxiety and hippocampal volume (experiment 2).

Given the potential confound of cosegregated biological differences between $\mathrm{HAB}$ and $\mathrm{LAB}$ rats such as depression, locomotion, or exploration, the functional significance of larger hippocampi in $\mathrm{HAB}$ rats cannot be inferred from our 
data. By contrast, the evidence provided for a reduction of hippocampal volumes with increasing anxiety-related behaviour in normal Wistar rats is robust as other factors can be assumed to be randomly distributed. Therefore, the safest assumption currently seems that, at least in normal rats, hippocampal volume and trait anxiety are inversely related. This interpretation is in line with the observed hippocampal volume reductions in animal models of hypercortisolemia and in PTSD patients cited earlier. The interpretation is, however, in conflict with the suggestion by Rusch et al (2001) of a positive relationship in humans, including healthy volunteers.

We note that Rusch et al's (2001) study was different to ours not only in terms of the subject population but also in a number of methodological aspects. Most importantly, our experimental design used objectively quantifiable behavioral measures that should have reduced variability compared to human studies where trait anxiety is measured using subjective verbal report. Moreover, subjective report can be strongly biased by a tendency to give socially desirable responses (Weinberger, 1990). This can lead to physiologically highly reactive subjects scoring low on trait anxiety (the so-called 'repressors'). It would be interesting to test whether repressor-type behavior can account for variability in morphometric measures.

It is also possible that the relationship between hippocampal volume and trait anxiety is more complicated than anticipated. It cannot be excluded that the behavioral indices employed in this study and the subjective reports in humans do not measure the same psychological construct. In particular, anxiety may be more multifaceted in humans than in rats, as is apparent from the proposed distinction between somatic and psychological anxiety (Beck et al, 1988). Clearly, further volumetric studies in humans assessing a broad range of symptoms and behaviors related to anxiety are warranted to reconcile the current findings.

In addition, we want to highlight that the volumetric differences between $\mathrm{HAB}$ and $\mathrm{LAB}$ rats are likely to have a strong hereditary component. This can be indirectly concluded from the genetic determination of behavioral differences, demonstrated by cross-fostering and crossbreeding experiments (Wigger et al, 2001).

In agreement with Rusch et al (2001), we found that anxiety had a stronger influence on hippocampal volume than depression-like behavior (experiment 2). This again highlights the potentially important role that anxiety plays in determining hippocampal volume. In the light of hippocampal volume loss in anxiety disorder (PTSD) and frequent anxiety comorbidity in depression, these data call for a closer investigation of the link between trait anxiety and hippocampal morphology.

In conclusion, we believe that further experiments in animals and humans explicitly testing the hypothesis of a negative relationship between hippocampal volume and anxiety and investigating underlying genetic/molecular causes are warranted.

\section{ACKNOWLEDGEMENTS}

We thank A Yassouridis for help with statistics and Marina Zimbelmann for help with experiments. AW was supported by a grant from Deutsche Forschungsgemeinschaft (DFG).

\section{REFERENCES}

American Psychiatric Association (2000). Diagnostic and Statistic Manual of Mental Disorders (DSM-IV-TR), 4th edn. APA: Washington, DC.

Beck AT, Epstein N, Brown G, Steer RA (1988). An Inventory for Measuring Clinical Anxiety: Psychometric Properties. J Consult Clin Psychol 56: 893-897.

Bremner JD, Randall P, Scott TM, Bronen RA, Seibyl JP, Southwick SM et al (1995). MRI-based measurement of hippocampal volume in patients with combat-related posttraumatic stress disorder. Am J Psychiatry 152: 973-981.

Bremner JD, Randall P, Vermetten E, Staib L, Bronen RA, Mazure $C$ et al (1997). Magnetic resonance imaging-based measurement of hippocampal volume in posttraumatic stress disorder related to childhood physical and sexual abuse - a preliminary report. Biol Psychiatry 41: 23-32.

Campbell S, Marriott M, Nahmias C, MacQueen GM (2004). Lower hippocampal volume in patients suffering from depression: a meta-analysis. Am J Psychiatry 161: 598-607.

Crusio WE, Schwegler H, Brust I, van Abeelen JH (1989). Genetic selection for novelty-induced rearing behavior in mice produces changes in hippocampal mossy fiber distributions. J Neurogen 5: 87-93.

De Bellis MD, Keshavan MS, Shifflett H, Iyengar S, Beers SR, Hall J et al (2002). Brain structures in pediatric maltreatment-related posttraumatic stress disorder: a sociodemogrpahically matched study. Biol Psychiatry 52: 1066-1078.

Fennema-Notestine C, Stein MB, Kennedy MC, Archibald SL, Jernigan TL (2002). Brain morphometry in female victims of intimate partner violence with and without posttraumatic stress disorder. Biol Psychiatry 51: 1089-1101.

Gilbertson MW, Shenton ME, Ciskewski A, Kasai K, Lasko NB, Orr SP et al (2002). Smaller hippocampal volume predicts pathologic vulnerability to psychological trauma. Nat Neurosci 5: 1242-1247.

Gray JA, McNaughton N (2000). The Neuropsychology of Anxiety, 2nd edn. Oxford University Press: Oxford.

Gurvits TV, Shenton ME, Hokama H, Ohta H, Lasko NB, Gilbertson MW et al (1996). Magnetic resonance imaging study of hippocampal volume in chronic, combat-related posttraumatic stress disorder. Biol Psychiatry 40: 1091-1099.

Hall CS (1934). Emotional behavior in the rat: I. Defecation and urination as measures of individual differences in emotionality. J Comp Psychol 18: 385-403.

Henderson ND, Turri MG, DeFries JC, Flint J (2004). QTL analysis of multiple behavioral measures of anxiety in mice. Behav Genet 34: 267-293.

Kalisch R, Elbel GK, Gossl C, Czisch M, Auer DP (2001). Blood pressure changes induced by arterial blood withdrawal influence BOLD signal in anesthesized rats at 7 Tesla: implications for pharmacologic MRI. Neuroimage 14: 891-898.

Keck ME, Welt T, Muller MB, Uhr M, Ohl F, Wigger A et al (2003). Reduction of hypothalamic vasopressinergic hyperdrive contributes to clinically relevant behavioral and neuroendocrine effects of chronic paroxetine treatment in a psychopathological rat model. Neuropsychopharmacology 28: 235-243.

Landgraf R, Wigger L (2002). High vs low anxiety-related behavior rats: an animal model of extremes in trait anxiety. Behav Gen 31: 371-382.

Landgraf R, Wigger A (2003). Born to be anxious: neuroendocrine and genetic correlates of trait anxiety in HAB rats. Stress 6: 111-119.

Landgraf R, Neumann ID (2004). Vasopressin and oxytocin release within the brain: a dynamic concept of multiple and variable modes of neuropeptide communication. Front Neuroendocrinol 25: $150-176$.

Lindauer RJ, Vlieger EJ, Jalink M, Olff M, Carlier IV, Majoie CB et al (2004). Smaller hippocampal volume in Dutch police 
officers with posttraumatic stress disorder. Biol Psychiatry 56 356-363.

Lyons DM, Yang C, Sawyer-Glover AM, Moseley ME, Schatzberg AF (2001). Early life stress and inherited variation in monkey hippocampal volumes. Arch Gen Psychiatry 58: 1145-1151.

MacQueen GM, Campbell S, McEwen BS, Macdonald K, Amano S, Joffe RT et al (2003). Course of illness, hippocampal function, and hippocampal volume in major depression. Proc Natl Acad Sci USA 100: 1387-1392.

Maguire EA, Gadian DG, Johnsrude IS, Good CD, Ashburner J, Frackowiak RS et al (2000). Navigation-related structural change in the hippocampi of taxi drivers. Proc Natl Acad Sci USA 97: 4398-4403.

McEwen BS (2000). Effects of adverse experiences for brain structure and function. Biol Psychiatry 48: 721-731.

Mechelli A, Crinion JT, Noppeney U, O'Doherty J, Ashburner J, Frackowiak RS et al (2004). Neurolinguistics: structural plasticity in the bilingual brain. Nature 431: 757.

Murgatroyd C, Wigger A, Frank E, Singewald N, Bunck M, Holsboer $\mathrm{F}$ et al (2004). Impaired repression at a vasopressin promoter polymorphism underlies overexpression of vasopressin in a rat model of trait anxiety. J Neurosci 24: 7762-7770.

Paxinos G, Watson C (1998). The Rat Brain in Stereotaxic Coordinates, 4th edn. Academic Press: San Diego.

Pellow S, Chopin P, File SE, Briley M (1985). Validation of open:closed arm entries in an elevated plus-maze as a measure of anxiety in the rat. $J$ Neurosci Methods 14: 149-167.

Porsolt RD, Anton G, Blavet N, Jalfre M (1978). Behavioural despair in rats: a new model sensitive to antidepressant treatments. Eur J Pharmacol 47: 379-391.

Rasmusson AM, Vythilingam M, Morgan III CA (2003). The neuroendocrinology of posttraumatic stress disorder: new directions. CNS Spectr 8: 651-657.

Rusch BD, Abercrombie HC, Oakes TR, Schaefer SM, Davidson RJ (2001). Hippocampal morphometry in depressed patients and control subjects: relations to anxiety symptoms. Biol Psychiatry 50: $960-964$.

Salome N, Salchner P, Viltart O, Sequeira H, Wigger A, Landgraf R et al (2004). Neurobiological correlates of high (HAB) versus low anxiety-related behavior (LAB): differential Fos expression in $\mathrm{HAB}$ and LAB rats. Biol Psychiatry 55: 715-723.

Stein MB, Koverola C, Hanna C, Torchia MG, McClarty B (1997). Hippocampal volume in women victimized by childhood sexual abuse. Psychol Med 27: 951-959.

Trullas R, Skolnick P (1993). Differences in fear motivated behaviors among inbred mouse strains. Psychopharmacology 111: 323-331.

Videbech P, Ravnkilde B (2004). Hippocampal volume and depression: a meta-analysis of MRI studies. Am J Psychiatry 161: 1957-1966.

Villarreal G, Hamilton DA, Petropoulos H, Driscoll I, Rowland LM, Griego JA et al (2002). Reduced hippocampal volume and total white matter volume in posttraumatic stress disorder. Biol Psychiatry 52: 119-125.

Weinberger DA (1990). The construct validity of repressive coping style. In: Singer JL (ed). Repression and Dissociation: Implications for Personality Theory, Psychopathology, and Health. Chicago University Press: Chicago.

Wigger A, Loerscher P, Weissenbacher P, Holsboer F, Landgraf R (2001). Cross-fostering and cross-breeding of HAB and LAB rats: A genetic rat model of anxiety. Behav Gen 31: 371-382.

Wigger A, Sánchez MM, Mathys KC, Ebner K, Liu D, Kresse A et al (2004). Alterations in central neuropeptide expression, release, and receptor binding in rats bred for high anxiety: critical role of vasopressin. Neuropsychopharmacology 29: 1-14.

Wolf OT, Dyakin V, Vadasz C, de Leon MJ, McEwen BS, Bulloch K (2002). Volumetric measurement of the hippocampus, the anterior cingulate cortex, and the retrosplenial granular cortex of the rat using structural MRI. Brain Res Brain Res Protoc 10: $41-46$. 